\title{
PROPOSED NEW EMPIRICAL EXPRESSION FOR NATURAL PERIOD OF RC TALL BUILDINGS IN INDIA
}

\author{
Pulkit Dilip Velani $^{1}$, RamancharlaPradeep Kumar ${ }^{2}$ \\ ${ }^{1}$ PhD Student, Earthquake Engineering Research Centre, IIIT Hyderabad, Telangana State, India. \\ ${ }^{2}$ Professor of Civil Engineering and Head of Earthquake Engineering Research Centre, IIIT Hyderabad, Telangana State, India.
}

\begin{abstract}
Urbanization is rapidly increasing in almost every city in India. Huge infrastructure developmental plans have been laid by the government and private organizations. Large advertising boards of tall buildings (ranging from 30 to 50 floors) already started attracting people to invest in these infrastructure plans. However, from the point of view of seismic hazard prevailing in the country, "Will these buildings survive during future earthquakes?" is a question to be answered before proceeding for construction. In last 2.5 decades, 7 moderate earthquakes have been witnessed: Bihar-Nepal border (M6.4) in 1988, Uttarkashi (M6.6) in 1991, Killari (M6.3) in 1993, Jabalpur (M6.0) in 1997, Chamoli (M6.8) in 1999, Bhuj (M6.9) in 2001, A\&N Islands (M9.3) in 2004, Muzaffarabad (M7.2) in 2005, Sikkim (M6.8) in 2011 and more recently Twin Earthquakes in the neighborhood Nepal. These earthquakes have clearly exposed the lack of understanding of seismic hazard of the country. Sometimes, even when the hazard is understood, the lack of knowledge is exposed on earthquake resistant design and construction practice of reinforced concrete structures. The professionals involved in building construction should be more concerned with the safety of building infrastructure during future earthquake events. Among several aspects, natural period of building is one of the crucial parameters which decide the seismic demand of the building. Present study focuses on developing an empirical expression of fundamental natural period of RC tall buildings in India with the help of ambient vibration tests. Through the study it is found that the periodheight relationship is most suitable to get the natural period of the building. It may be noted that the proposed empirical expression is derived from the data of 32 buildings and the same can be improved upon testing more number of buildings.
\end{abstract}

\section{Keywords: Fundamental Natural Period, Tall Buildings, Ambient Vibration and Earthquake Resistant Design}

\section{INTRODUCTION}

Urbanization is rapidly increasing in India. The average height of building in metropolitan cities is increasing dayby-day. There are several earthquake safety issues involved in planning, designing and constructing tall buildings. Some issues related to seismic behavior are still not resolved even in developed countries, like USA and Japan. The situation in India is that there are few codes which specify guidelines for earthquake resistant design of structures. However, the guidelines given in this code are useful for regular and relatively small, low-rise buildings. The seismic design of tall building becomes very important since tall buildings are sensitive to large distance earthquakes. The damage to these buildings because of large earthquake at great distance can be equal to the damage caused by near filed moderate earthquake. For areas with low seismicity wind load will govern the design of buildings. The wind induced vibration should be controlled such that it satisfies the serviceability requirements. Although wind tunnel model gives a lot of insight about the possible wind load to be resisted by tall building because of surrounding, but it is always good practice to verify this assumption by full scale experiment work for better understanding of wind load and to optimize the design of such buildings in future.

When it comes to tall buildings, every structure is special, several parameter needed to be considered. One such parameter is fundamental natural period, ' $T$ '. In case of seismic design of building the fundamental natural period helps in finding out the base shear to be resisted by the structure and mode shape gives the distribution of base shear at every storey. For equivalent static method [1], which is very common philosophy in many seismic codes around the world, the fundamental period will decide the spectral acceleration coefficient (Fig - 1) and there by the seismic demand i.e., base shear to be resisted by the structure. Over estimation of the time period values from computer based analysis gives the lower value of design base shear which is not true in reality. The value arrived by such analysis is not reliable because of non-availability of accurate modeling of unreinforced masonry (URM) infill walls in a software package. Substantial skill is required to overcome modeling challenges such as material property, boundary conditions, stiffness contribution of nonstructural elements etc.

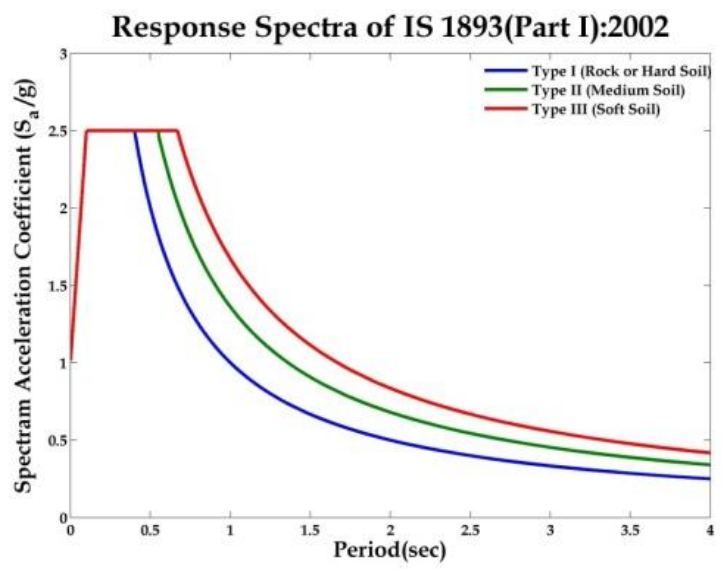

Fig -1: Design Acceleration Spectrum 
At initial stage in design of building, when the exact size of the structural members is unknown, the fundamental time period can be calculated by the empirical expression suggested by the seismic code of a country. Traditionally this empirical period formulae are derived from the measured period of buildings which were shaken strongly but not deformed into the inelastic range. Such a data is most useful but slow to accumulate as it involves installation of permanent accelerometer and earthquake causing strong shaking of such buildings is infrequent in nature [2]. In the absence of such data, one can go for a period measured by ambient vibration technique.

The upcoming draft code for tall building [3] is silent over the expression of fundamental natural period of $\mathrm{RC}$ tall buildings. In absence of such expression one has to go with IS 1893:2002 recommendations. There is no explicit formula defined in IS 1893:2002 for RC SW structural system hence such type of empirical expression of RC MRF building with infill wall, $\mathrm{T}=0.09 \mathrm{H} /(\mathrm{D}) 0.5$. Current approximate formulae present in the IS 1893:2002 are adopted from an earlier version of US codes which are based on the measured period of US buildings, shaken in the elastic range, during Californian earthquakes (Fig - 1). Ambient vibration tests conducted by Arlekar\&Murty [4] on 19 RC MRF buildings with brick masonry infill walls in Kanpur indicated that the Indian code expression for fundamental natural periods are inadequate for Indian buildings. Hence there is a need to check the applicability of the existing formulae and if necessary a new formula should be tailored for buildings in India.

This paper presents the results of ambient vibration tests on 32 high-rise reinforced buildings whose measured period are compared with Indian codal provision. Study also compares the proposed expression with the expression recommended in other country codes.

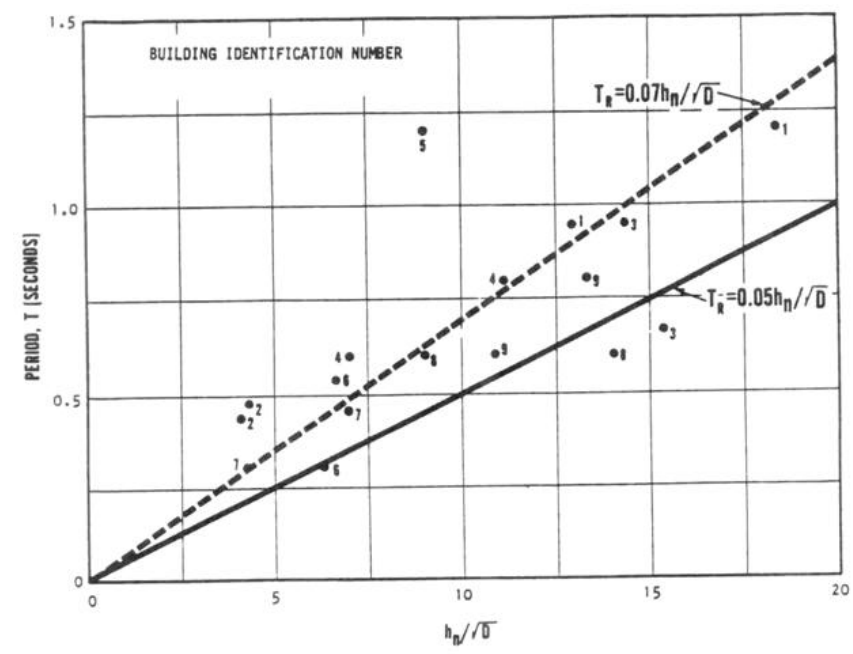

Fig - 1: Observations on RC frame buildings during San Fernando Earthquake (From FEMA 369, 2001)

\section{PERIOD OF VIBRATION OF REINFORCED CONCRETE BUILDINGS}

Generally the fundamental period of RC buildings are correlated with number of stories, height of the building, width of the building along the direction of shaking and the wall area present at ground storey. There is no explicit formula defined in IS 1893:2002 for RC tall buildings hence such type of building has to use Eq. (1).

$$
T=\frac{0.09 H}{\sqrt{D}}
$$

Where ' $H$ ' is the he Height of building, $\mathrm{m}$. This excludes the basement storeys, where basement walls are connected with the ground floor deck or fitted between the building columns. But it includes the basement storeys, when they are not so connected. And ' $D$ ' is the base dimension of the building at the plinth level, in $\mathrm{m}$, along the considered direction of the lateral force.

In ATC3-06 [5] in Eq. (1), $H / \sqrt{d}$ was multiplied by 0.05 as shown inFig - 1 , when ' $H$ ' and ' $D$ ' are in feet. As discussed by Pinho and Crowley [6] this formula comes from the equation of the frequency of vibration of a cantilever (considering shear deformation only), with the thickness of the wall considered to be more or less constant and thus only the width/length of the building is an input parameter, as presented in Eq. (2).

$$
T=4 \sqrt{\frac{m}{\kappa G}} \frac{H}{\sqrt{A}}=\frac{\alpha H}{\sqrt{A}}=\frac{\alpha H}{\sqrt{D t_{w}}}=\frac{\alpha_{1} H}{\sqrt{D}}
$$

Where ' $m$ ' is the mass per unit length, ' $G$ ' is the shear modulus, ' $k$ ' is the shape factor to account for non-uniform distribution of shear stresses, ' $D$ ' is the length of the cantilever, ' $t_{w}$ ' is the thickness. Some codes use this formula specifically for buildings with both frames and shear walls, some use the equation for reinforced concrete MRF with masonry infill panels, but many specify it for use with any building except moment resisting space frames. There are many countries which adopted such formula, including, but not limited to, are ATC3-06:1978 [5], IS 1893-1984 [7], KBC 1988 [8], NBCC 1995 [9].

There are few explicit studies conducted in past, targeting only multistoried buildings. One of such first kind of studies was conducted by Ellis in 1980 [10]. This study came up with the Eq. (3) based on the results of measurements taken on 162 multi-storey buildings. Where $H$ is height if the building in meter. All buildings in this study were of rectangle in plan and first mode natural period were taken into consideration for arriving Eq. (3). This equation was adopted into the Code of Practice on Wind Effects in Hong Kong 2004 [11], the Australian and New Zealand Standard AS/NZS 1170.2 [12], and the Eurocode ENV1991-2-4 [13].

$$
T=\frac{H}{46}
$$


One of the studies focused on finding damping of buildings for wind resistance design of tall building came up with the similar equation with change in denominator value[14]. This study came up with Eq. (4) based on filed measurements taken in Japan for habitability levels of acceleration and deflection of tall buildings.

$$
T=\frac{H}{67}
$$

Where $H$ is height of the building in meter. The reason in difference in Eq. (3) and Eq. (4) is because Eills data base has all tall buildings with rectangular plans. Whereas later study in 2000 consist of buildings with different shapes. Architectural Institution of Japan [15] conducted similar study across Japan and came up with empirical expression for micro vibration of RC tall buildings (Fig - 2).

AIJ[15] proposed Eq. (5) which is similar to Tamura et. al. proposals.

$$
T=\frac{H}{66.67}
$$

The average height of buildings in Indian cities has risen over last 2 decades. Hence there is an urgent need to check the applicability of the existing formula for natural period.

\section{PERIOD OF VIBRATION OF REINFORCED}

\section{CONRETE TALL BUILDINGS}

\subsection{Ambient Vibration Test}

Ambient vibration tests can capture the linear behaviour of the structure. Hence in the absence period data measured during actual earthquake events one can go for a period measured by ambient vibration technique. This is true because the energy required to deform the structure in the fundamental mode of vibration is the least. The contribution of the fundamental mode is usually dominant in the ambient vibration response of the structure. Thus, the approach of deriving dynamic characteristics of a structure by ambient vibration measurement is considered adequate only for ascertaining the properties associated with the fundamental mode of vibration. The source of ambient vibration can be wind, sea waves, vehicles, machinery and human produced excitation. And the source of ambient vibration will vary based on the structure e.g., ambient noise because of wind will be predominant in tall buildings compare to that in the short buildings.

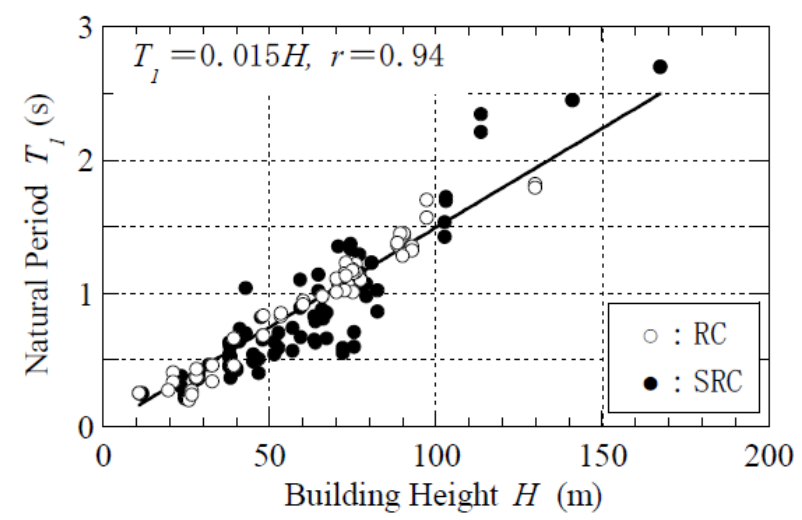

Fig - 2: Expression of Natural period of RC Tall building by AIJ [15]

Trifunac [16] stated that though forced and ambient vibration testing is based on small levels of excitation, compared to strong earthquake ground motions, but still it offers a sound basis for rational improvements in the vibration theory. In 1997, 19 reinforced concrete (RC) moment resisting frame (MRF) buildings, with unreinforced masonry (URM) infill walls, were surveyed by ambient vibration survey in order to develop the empirical expression for the fundamental period of Indian buildings [17].

\subsection{Investigated Buildings}

Thirty two numbers of RC buildings having more than 45 meter height, located in Hyderabad and Mumbai city were surveyed. The variation in number of floors is from sixteen to forty-two and majority of them are either residential with couple of building used for commercial purpose. The average floor-to-floor height of residential building was ranging between 2.9 to $3.4 \mathrm{~m}$ with only exception of MUM07 building having $3.60 \mathrm{~m}$ as floor-to-floor height. Whereas for commercial buildings, floor-to-floor height is 3.75 to $3.9 \mathrm{~m}$. The variation in height at ground storey or basement was a common feature. The building features discussed above are summarized in Table 1. Typical RC high-rise buildings surveyed in this study are shown inFig 3.

\begin{tabular}{|c|c|c|c|c|c|c|c|c|c|}
\hline \multirow[b]{2}{*}{ S. No. } & \multirow{2}{*}{$\begin{array}{l}\text { Building } \\
\text { ID }\end{array}$} & \multirow{2}{*}{$\begin{array}{l}\text { Number } \\
\text { of Storey }\end{array}$} & \multirow[b]{2}{*}{$\begin{array}{c}\text { Height } \\
\text { (m) }\end{array}$} & \multirow{2}{*}{$\begin{array}{l}\text { Typical } \\
\text { F.F. } \\
\text { Height } \\
(\mathrm{m})\end{array}$} & \multirow[b]{2}{*}{ Type } & \multicolumn{2}{|c|}{ Dimensions (m) } & \multicolumn{2}{|c|}{ Time period (sec) } \\
\hline & & & & & & $\begin{array}{c}\text { Longer } \\
\text { (L) }\end{array}$ & $\begin{array}{c}\text { Shorter } \\
\text { (D) }\end{array}$ & $\begin{array}{c}\text { Longer } \\
\text { (TL) }\end{array}$ & $\begin{array}{c}\text { Shorter } \\
\text { (TD) }\end{array}$ \\
\hline 1 & HYB40 & 16 & 46.21 & 2.82 & Residential & 53.42 & 43.28 & 0.630 & 0.671 \\
\hline 2 & HYB48 & 16 & 47.95 & 3.00 & Residential & 27.27 & 27.13 & 0.671 & 0.602 \\
\hline 3 & HYB49 & 16 & 47.95 & 3.00 & Residential & 28.00 & 24.00 & 0.573 & 0.671 \\
\hline 4 & HYB50 & 16 & 47.95 & 3.00 & Residential & 27.27 & 27.14 & 0.677 & 0.522 \\
\hline 5 & HYB39 & 17 & 50.81 & 2.82 & Residential & 45.82 & 42.75 & 0.620 & 0.738 \\
\hline 6 & HYB44 & 17 & 51.15 & 3.00 & Residential & 27.27 & 27.14 & 0.700 & 0.569 \\
\hline 7 & HYB45 & 17 & 51.15 & 3.00 & Residential & 28.00 & 24.00 & 0.593 & 0.688 \\
\hline
\end{tabular}

Table 1: Fundamental Period of RC buildings of height greater than $45 \mathrm{~m}$ measured using ambient vibration 


\begin{tabular}{|c|c|c|c|c|c|c|c|c|c|}
\hline 8 & HYB46 & 17 & 51.15 & 3.00 & Residential & 27.27 & 27.14 & 0.688 & 0.630 \\
\hline 9 & HYB47 & 17 & 51.15 & 3.00 & Residential & 27.27 & 27.14 & 0.682 & 0.625 \\
\hline 10 & HYB51 & 17 & 51.15 & 3.00 & Residential & 27.27 & 27.13 & 0.645 & 0.616 \\
\hline 11 & HYB52 & 17 & 51.15 & 3.00 & Residential & 40.53 & 28.00 & 0.650 & 0.569 \\
\hline 12 & HYB43 & 17 & 52.98 & 3.00 & Residential & 43.11 & 40.38 & 0.694 & 0.751 \\
\hline 13 & MUM05 & 20 & 58.60 & 2.90 & Residential & 30.74 & 19.91 & 0.987 & 0.811 \\
\hline 14 & MUM02 & 21 & 63.00 & 3.00 & Residential & 49.07 & 24.80 & 1.137 & 1.154 \\
\hline 15 & HYB12 & 22 & 65.60 & 3.00 & Residential & 28.94 & 26.56 & 0.920 & 0.963 \\
\hline 16 & HYB13 & 22 & 65.60 & 3.00 & Residential & 44.55 & 28.97 & 0.952 & 0.910 \\
\hline 17 & HYB53 & 22 & 66.00 & 2.95 & Residential & 27.00 & 27.00 & 1.050 & 1.050 \\
\hline 18 & MUM14 & 22 & 66.00 & 3.00 & Residential & 26.40 & 23.30 & 1.365 & 1.204 \\
\hline 19 & HYB18 & 22 & 66.00 & 3.00 & Residential & 81.08 & 25.45 & 1.078 & 1.154 \\
\hline 20 & HYB23 & 17 & 66.23 & 3.90 & Commercial & 67.64 & 24.45 & 0.871 & 1.154 \\
\hline 21 & MUM01 & 23 & 69.00 & 3.00 & Residential & 49.07 & 24.80 & 1.122 & 1.388 \\
\hline 22 & MUM15 & 25 & 71.86 & 3.00 & Residential & 24.67 & 13.63 & 1.107 & 1.545 \\
\hline 23 & MUM03 & 25 & 75.00 & 3.00 & Residential & 48.19 & 40.62 & 1.412 & 1.365 \\
\hline 24 & MUM16 & 26 & 77.86 & 3.00 & Residential & 37.60 & 16.80 & 1.222 & 1.545 \\
\hline 25 & HYB20 & 27 & 81.00 & 3.00 & Residential & 73.43 & 20.58 & 1.170 & 1.280 \\
\hline 26 & HYB32 & 26 & 83.60 & 3.26 & Residential & 50.46 & 42.31 & 1.138 & 1.122 \\
\hline 27 & HYB42 & 28 & 86.37 & 3.00 & Residential & 43.11 & 40.38 & 1.388 & 1.154 \\
\hline 28 & HYB19 & 24 & 87.14 & 3.75 & Commercial & 80.26 & 46.03 & 1.241 & 1.204 \\
\hline 29 & MUM08 & 31 & 90.95 & 2.90 & Residential & 52.54 & 35.18 & 1.517 & 1.638 \\
\hline 30 & MUM06 & 37 & 119.60 & 3.20 & Residential & 46.39 & 29.72 & 1.780 & 2.340 \\
\hline 31 & MUM07 & 37 & 137.70 & 3.60 & Residential & 51.54 & 37.85 & 2.340 & 2.642 \\
\hline 32 & HYB31 & 42 & 146.75 & 3.40 & Residential & 33.34 & 29.50 & 3.033 & 3.033 \\
\hline
\end{tabular}

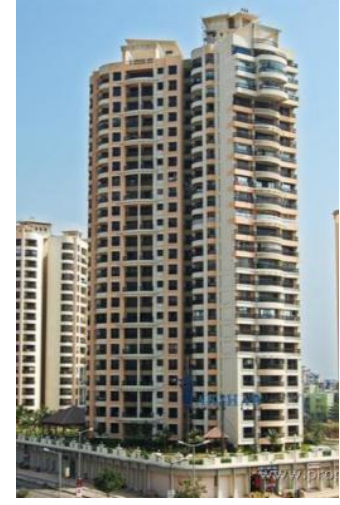

(a)

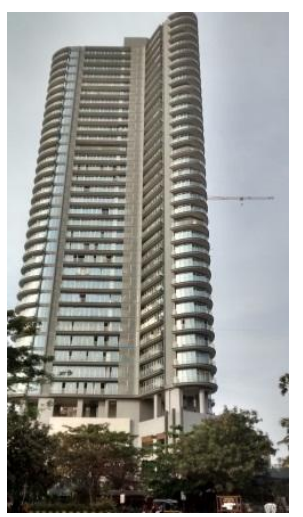

(b)

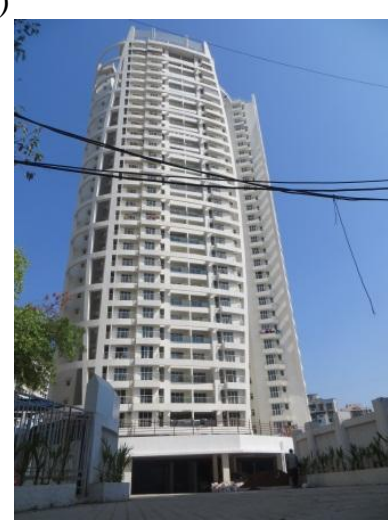

(c)

Fig - 3: Examples of typical high-rise buildings (a) MUM03 (b) MUM07 and (c) MUM08

\subsection{Testing Equipment and Procedure}

For this study, relatively low price and high performance micro-tremor portable 'IT Kyoshin' Vibration sensor was used, which was developed as a part of Indo-Japan collaborative research project (DISANET) sponsored by JST and JICA. These force balance acceleration sensors can measure recording of range $+0.25 \mathrm{~g}$ to $-0.25 \mathrm{~g}$ in resolving power $5310-3 \mathrm{~cm} / \mathrm{sec} 2$. The resolving power of the AD converter are 24 bits. However, effective resolving power is 18 bit equivalency. This vibration sensor was connected with Ethernet cable to the mac book to store the vibration data. A single point observation at the roof top or maximum accessible floor level was recorded for 15-45 minutes. Whenever possible the sensor was kept very near to the center of the building and readings are taken at the rate of 100 data points per second. Sensors are aligned and leveled (Fig - 4), in such a way that two horizontal axes of the sensor become parallel to the longitudinal and transverse direction of the building.

\subsection{Result of Experimental Analysis}

Table 1 shows the fundamental period values of buildings along longer and shorter direction which are identified based on the Fourier spectrum analysis. MATLAB code has been written to do analysis of the recorded data. Typical procedure consists of reading a 15-30 min raw data, stored 
in mac book, and doing a baseline correction. Butterworth band pass filter was designed for removal of noise and unwanted frequencies. Based on user input lower and higher cutoff frequencies, the filter is capable of filtering the frequency of order four. Baseline and filtered time history are divided in to one minute window and fifteen numbers of undisturbed windows are selected for further analysis.

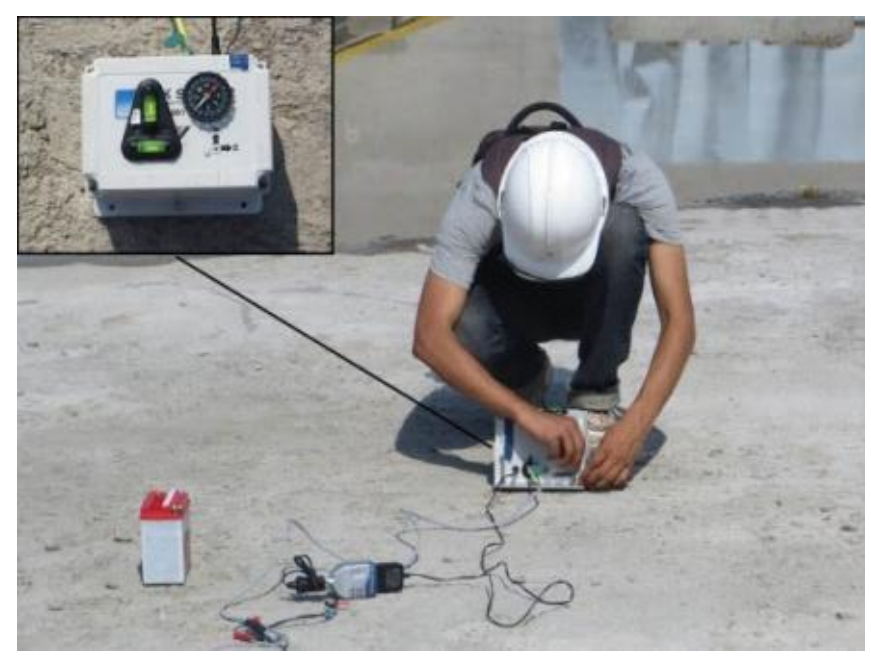

Fig - 4: Leveling and Aligning of sensor on roof top

The Fourier spectrum of this fifteen number of one minute window is computed (Fig - 5) and finally average spectrum of this fifteen minute data is plotted to identify the fundamental natural frequency of the structure (Fig - 6), along the direction under consideration. Inverse of frequency will give us the desire fundamental natural period of the building in seconds.

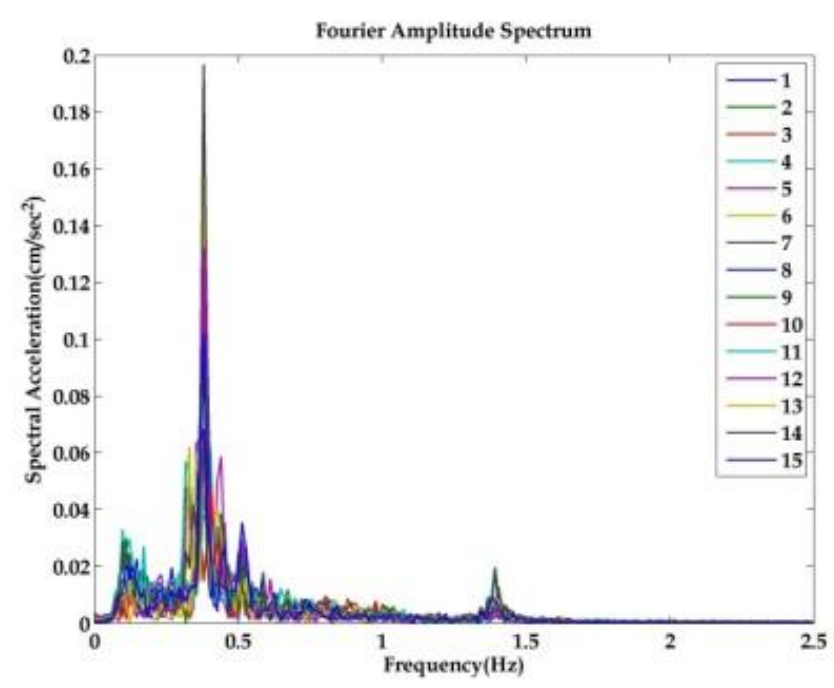

Fig - 5: Example of Fourier Amplitude Spectrums of fifteen one minute window of building (MUM07) along shorter (NS) direction

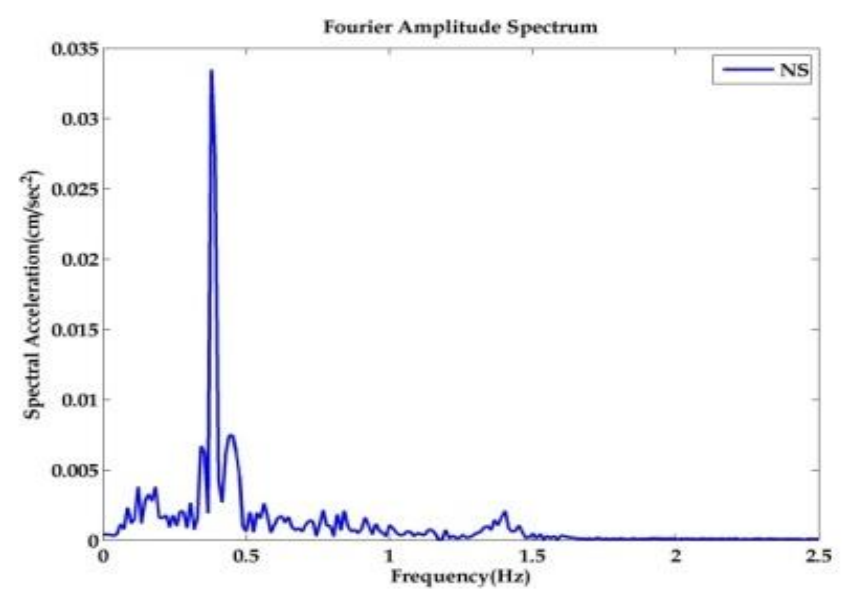

Fig - 6:Example of Fourier Amplitude Spectrums of fifteen one minute window of building (MUM07) along shorter (NS) direction

\section{REGRESSION ANALYSISS OF MEASURED PERIOD}

Regression analysis is carried out to establish the relationship between the fundamental period and the building parameters. The power law and linear regression analysis is adopted to establish the relation between the period and the various building parameters such as height (' $H$ '), width (' $D$ ') and product of lateral dimension (' $A$ ') of the buildings. In such analysis, both variables are often transformed by means of a logarithm. The resulting data is plotted on a "log-log" scale, where a linear model is then fit by Eq. (6).

$$
y=a_{1}+a x
$$

Where $y=\log (T)$ and $x=\log \left(H / D^{0.5}\right)$ or $\log (H / D)$ or $\log$ $\left(H / A^{0.5}\right)$ or $\log (H)$. The parameter ' $a_{l}$ ' and ' $a$ ' are determined by minimizing the squared error between the measured period and computed periods, and then ' $C_{t}$ ' was back calculated from the relationship $a_{l}=\log \left(C_{t}\right)$.

The evaluation of the regression analysis is done with the help of standard error of estimate $S_{e}$ (Eq. (7)) and the coefficient of determination $R^{2}$ (Eq. (8)). The expression with the coefficient of determination close to 1.0 represents a good fit. The upper and lower bound were also calculated by adding or subtracting $S_{e}$ from the $C_{t}$ value (Eq. (9) and (10)). Lowering the ' $C_{t}$ ' is done because ' $S_{e}$ ' approaches the standard deviation for large number of samples and we will get ' $C_{t_{\text {low }}}$ ' which will ensure that $15.9 \%$ of the measured periods would fall below the curve corresponding to it. If desired, one can also go for ' $\mathrm{C}_{\mathrm{t}_{\text {low }}}{ }^{\prime}$ corresponding to some other non exceedance probabilities.

$$
\begin{gathered}
S_{e}=\sqrt{\frac{\sum\left(\log T_{i}-\log \bar{T}_{i}\right)^{2}}{n-2}} \\
R^{2}=1-\frac{n \sum\left(\log T_{i}-\log \bar{T}_{i}\right)^{2}}{\left(n \sum \log T_{i}^{2}\right)-\left(\log T_{i}\right)^{2}}
\end{gathered}
$$




$$
\begin{gathered}
\log C_{t_{\text {low }}}=\log C_{t}-S_{e} \\
\log C_{t_{\text {upper }}}=\log C_{t}+S_{e}
\end{gathered}
$$

Where ' $T_{i}{ }^{\prime}$ and ' $\bar{T}_{i}$ ' are the ' $i$ 'th, data and regression estimate values of natural periods, respectively. And ' $n$ ' is the total number of data points.

The regression analysis carried out on the data tabulated in Table 1. It consists of buildings from 16-42 storeys with a height variation of $46-147 \mathrm{~m}$. The fundamental period variation was found to be 0.522 to $3.033 \mathrm{sec}$.

The most relevant expression of such buildings in IS 1893:2002 is, $T=0.09 H / \sqrt{D}$. The plot of comparison between the measured period and codal provision is shown inFig - 7. Though this underestimates the period of most of the buildings but have very poor $R^{2}=0.691$ with $S_{e}=0.243$.

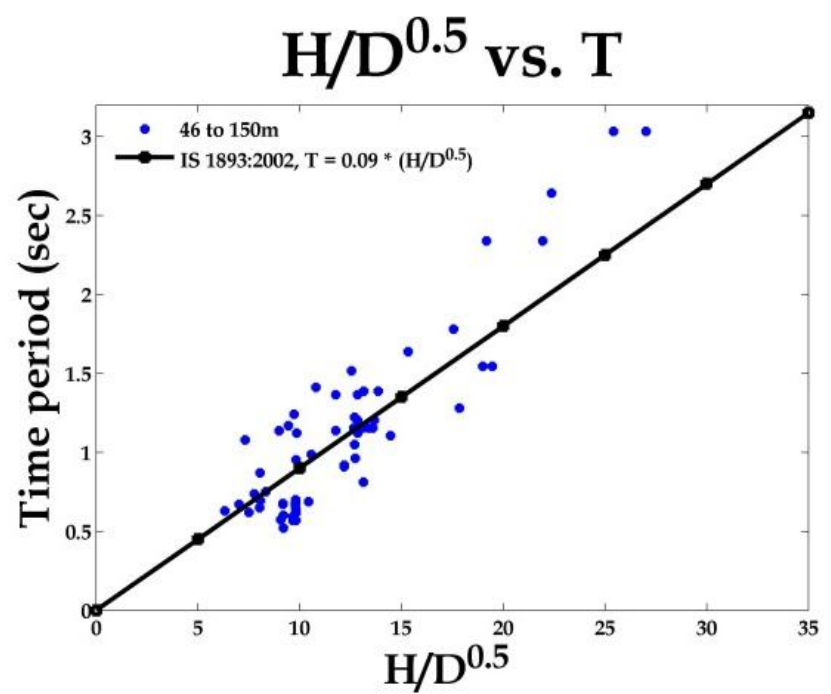

Fig - 7: Comparison of measured period of RC buildings of height above $45 \mathrm{~m}$ with IS 1893:2002
Regression analysis carried out for $H, H / D^{0.5}, H / D$ and $H / A^{0.5}$ and results are tabulated in Table 2. Among various relationships once again relationship between $T$ and $H$ found to be optimum. Unconstrained regression analysis between $T$ and $H$ gave expression $T=0.003 H^{1.36}$ with $S_{e}=0.137$ and $R^{2}=0.902$. It is desirable that the expression for natural period be easy to remember hence constrained model with power $=1.35$ was computed which gave same $S_{e}$ and $R^{2}$ values. Hence one can adopt of this proposal. A lower bound expression for RC buildings height greater than $45 \mathrm{~m}$ with infill wall panels can be used as Eq. (11). Where ' $H$ ' is height of the building in metre and ' $T$ ' in seconds. The plot of this expression with the measured period is shown in Error! Reference source not found.

$$
T=0.003 H^{1.35}
$$

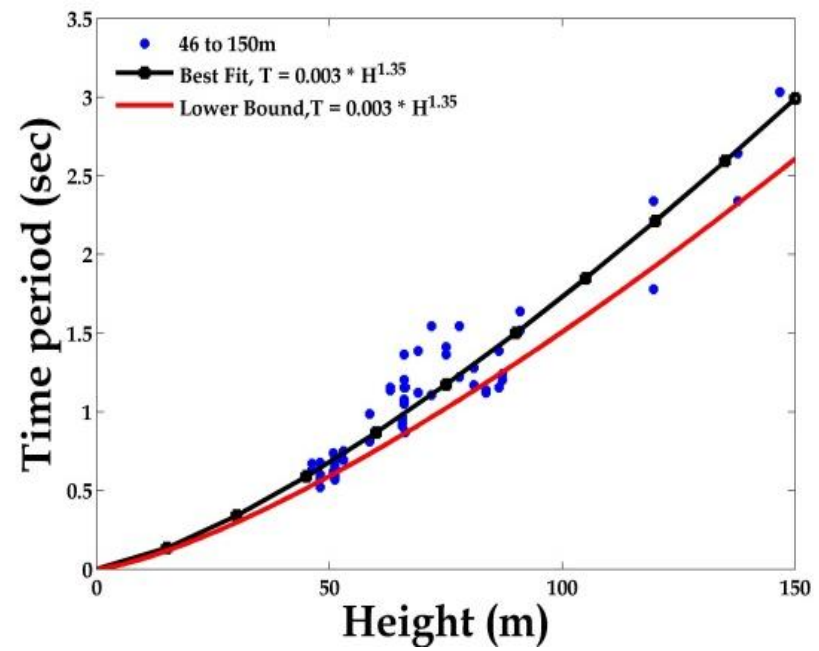

Fig - 8: Plot of experimental data and proposal expression for natural period of RC buildings of height above $45 \mathrm{~m}$ with infill wall panel

Table 2: Regression models result for Building above 20 storey ( $>60 \mathrm{~m})$

\begin{tabular}{|c|c|c|c|c|c|c|}
\hline Model & $\boldsymbol{C}_{\boldsymbol{t}}$ & $\boldsymbol{a}$ & $\boldsymbol{S}_{\boldsymbol{e}}$ & $\boldsymbol{R}^{2}$ & $\boldsymbol{C}_{\text {low }}$ & $\boldsymbol{C}_{\text {upper }}$ \\
\hline$T=C_{t} H^{a}$ & 0.003 & 1.36 & 0.137 & 0.902 & 0.003 & 0.004 \\
\hline $\boldsymbol{T}=\boldsymbol{C}_{t} \boldsymbol{H}^{\boldsymbol{a}}$ & $\mathbf{0 . 0 0 3}$ & $\mathbf{1 . 3 5}$ & $\mathbf{0 . 1 3 7}$ & $\mathbf{0 . 9 0 2}$ & $\mathbf{0 . 0 0 3}$ & $\mathbf{0 . 0 0 4}$ \\
\hline$T=C_{t} H^{a}$ & 0.015 & 1.00 & 0.176 & 0.838 & 0.013 & 0.018 \\
\hline$T=C_{t}\left(\frac{H}{\sqrt{D}}\right)^{a}$ & 0.057 & 1.17 & 0.234 & 0.713 & 0.045 & 0.072 \\
\hline$T=C_{t}\left(\frac{H}{\sqrt{D}}\right)^{a}$ & 0.060 & 1.15 & 0.234 & 0.713 & 0.048 & 0.076 \\
\hline$T=C_{t}\left(\frac{H}{\sqrt{D}}\right)^{a}$ & 0.087 & 1.00 & 0.241 & 0.698 & 0.068 & 0.111 \\
\hline$I S 1893: 2002$ & 0.090 & 1.00 & 0.243 & 0.691 & 0.071 & 0.115 \\
\hline$T=C_{t}\left(\frac{H}{D}\right)^{a}$ & 0.654 & 0.62 & 0.355 & 0.342 & 0.459 & 0.933 \\
\hline$T=C_{t}\left(\frac{H}{\sqrt{A}}\right)^{a}$ & 0.550 & 0.87 & 0.327 & 0.442 & 0.397 & 0.763 \\
\hline
\end{tabular}




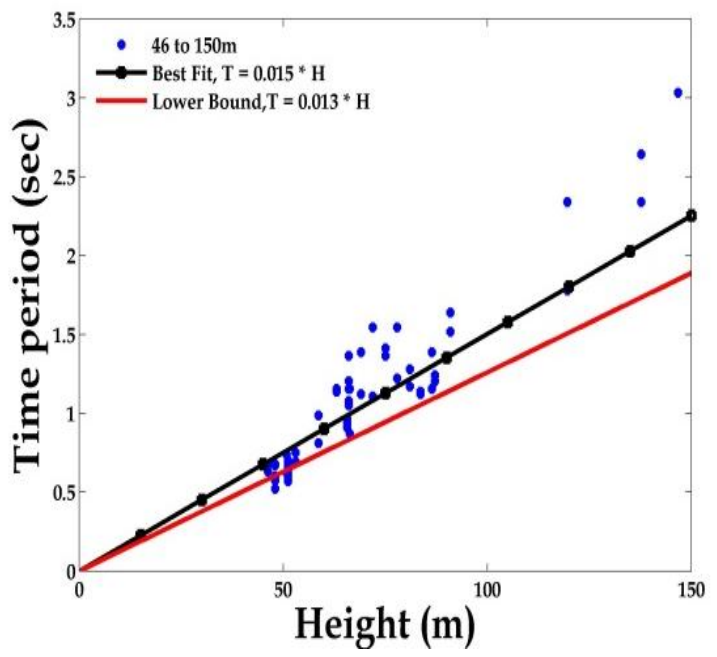

Fig - 9: Plot of experimental data and proposal expression for natural period of RC buildings of height above $45 \mathrm{~m}$ with infill wall panel

Eq (11) looks perfect but fundamental period gets saturated after some height. This trend of saturation of period is not visible with existing data. Larger database of period values may help to derive the true relationship. Hence keeping the benchmark of previous research around the word [10,14] another linear regression model is worked out (Fig - 9) by keeping height as single parameter without any power. This constrained regression analysis with power as 1 , between $T$ and $H$, gave expression $T=0.015 H$ with $S_{e}=0.176$ and $R^{2}=$ 0.838. A lower bound value is computed and proposed equation is

$$
T=0.013 H
$$

Eq (12) matches (Fig - 10) with the relationship derived by Tamura [12] and AIJ [15] based on Japanese RC all buildings.

\section{DISCUSSION AND CONCLUSIONS}

There is increase in construction of tall buildings in Indian metro cities. But upcoming Indian code for tall building is silent over expression for natural period of tall building. This is because India has very less or no instrumented building which can provide data to arrive with period expression. In this study, ambient vibration data from 32 tall buildings is used derive empirical expression for natural period of tall buildings.

From the present study, the empirical expression for estimating the fundamental natural periods for RC Tall buildings with infill panels whose height is between 46-150 $\mathrm{m}$ is derived as $\boldsymbol{T}=\mathbf{0 . 0 1 3 H}$, where, $H$ is height of building from the base (in m). In future, such expression should be revised periodically by expanding database of building natural periods. Involvement of government agencies would help in getting the true representative samples of buildings from different parts of the country with different seismic zones.

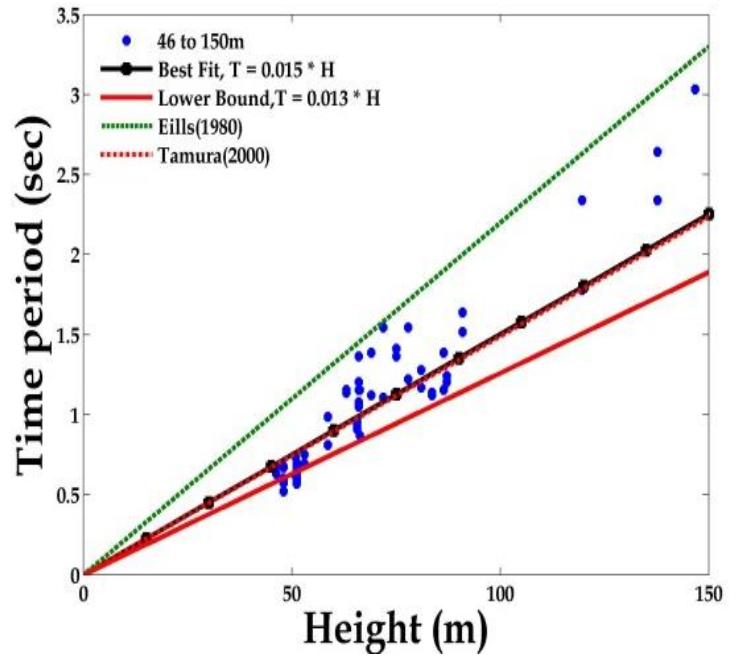

Fig - 10: Comparison of proposed equation with the past literature

\section{REFERENCES}

[1]. IS 1893 (Part 1) :2002 : Indian standard Criteria for earthquake resistant design of structures. Bureau of Indian Standards, New Delhi, India.

[2]. Goel R, Chopra A (1997), "Period Formulas for Moment-Resisting Frame Buildings", Journal of Structural Engineering, November, 123 (11), 14541461.

[3]. CED 38 (2016), Criteria for Structural Safety of Tall Buildings. Bureau of Indian Standards,New Delhi, India.

[4]. Arlekar JN, Murty CVR (2000): Ambient vibration urvey of RC-frame builings having brick masonry walls.The Indian Concrete Journal, October, 74(10),581-586.

[5]. ATC3-06 (1978): Tentative provisions for the development of seismic regulations for buildings, Rep. No, ATC3-06, Applied Technological Council, Palo Alto, California.

[6]. Crowley H, Pinho R (2010): Revisiting Eurocode 8 formulae for periods of vibration and their employment in linear seismic analysis.Earthquake Engineering \& Structural Dynamics,39(2), 223-235.

[7]. IS 1893 : 1984: Indian standard Criteria for earthquake resistant design of structures. Bureau of Indian Standards, New Delhi, India.

[8]. National Building Code of Korea. 1988, TheMinstry of Construction.

[9]. National Building code of Canada, 1995. Associate Committee on the National Building Code, National Research Council of Canada.

[10].Ellis, B.R. (1980), “As assessment of the accuracy of predicting the fundamental natural frequencies of buildings and the implications concerning the dynamic analysis of structures", Proceedings of the Institution of Civil Engineers, Part 2, vol. 69, Sept., 763-776.

[11].Code of Practice on Wind Effects in Hong Kong. (2004), Buildings Department of the Government of the HongKong SAR. 
[12].AS/NZS 1170.2. (2002). Australian/New Zealand Standard, Structural design actions, Part 2: Wind actions.Standards Australia \& Standards New Zealand.

[13].Eurocode ENV1991-2-4. (1994), EUROCODE 1: Basis of Design and Actions on Structures, Part 2.4: WindActions, CEN/TC 250/Sc1.

[14].Tamura, Y., Suda, K., and Sasaki, A. (2000), "Damping in buildings for wind resistant design", Proc. Int'l Symp. on Wind and Structures (Cheju), Techno-Press, Korea, pp.115-130.

[15].AIJ (2000), Damping in Buildings.Architectural Institution of Japan, Tokyo, Japan.

[16].Trifunac MD (1972): Comparisions between ambient and forced vibration experiments.Earthquake Engineering and Structural Dynamics, 1,133-150.

[17].Arlekar JN (1997):Ambient vibration survey of reinforced concrete frame buildings with unreinforced brick masonry infill.Thesis submitted to Department of Civil Engineering, Kanpur for M.Tech, Indian Institute of Technology - Kanpur, India.

\section{BIOGRAPHIES}

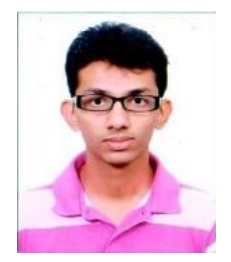

Pulkit Dilip Velani is pursuing $\mathrm{PhD}$ (Civil) from International Instituteof Information Technology, Hyderabad. He holds MS and $\mathrm{BE}$ in Civil engineering from IIIT-H and Mumbai University, respectively. His research interests are structural health monitoring, earthquake resistant analysis and design of RC building, analysis and design of tall building and Non-Destructive testing.

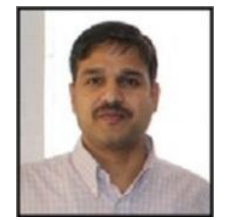

R. Pradeep Kumar holds a PhD degree in civil engineering from University of Tokyo, Japan. He is Professor of Civil Engineering and Head of Earthquake Engineering Research Centre (EERC) at International Institute of Information Technology, Hyderabad. His research interests are numerical modeling of faults and tectonicplates, collapse simulation of buildings, seismic evaluation and strengthening of buildings, seismic safety of heritage structures and concrete codes in India. Presently he is a panel member of IS 456 and IS 1893. 